EESTI NSV TEADUSTE AKADEEMIA TOIMETISED. 29. KOIDE KEEMIA. 1980, NR. 4

ИЗВЕСТИЯ АКАДЕМИИ НАУК ЭСТОНСКОИ ССР. ТОМ 29 ХимИЯ. 1980, № 4

Анне ОРАВ, Кай КУНИНГАС, Сильвия РАНГ, О. ЭЙЗЕН

\title{
КАПИЛЛЯРНАЯ ГАЗОВАЯ ХРОМАТОГРАФИЯ Н-АЛКИНОВ НА ПОЛИЭТИЛЕНГЛИКОЛЕ 20М
}

В $\left[{ }^{1-3}\right]$ нами было установлено, что полиэтиленгликоль (ПЭГ) 4000 селективно разделяет изомеры $H$-алкинов. Целью настоящей работы является исследование возможности разделения и идентификации н-алкинов с помощью высшего гомолога ПЭГ 4000 - термически более стабильного ПЭГ $20 \mathrm{M}$.

\section{Экспериментальная часть}

Работу проводили на хроматографе «Хром-3» с пламенно-ионизационным детектором. Капиллярная колонка из нержавеющей стали $(100 \mu \times 0,25$ мм) была покрыта жидкой фазой динамическим методом. Эффективность колонки по 2-децину при $130^{\circ} \mathrm{C}$ составляла $\sim 160000$ TT.

' Рабочие условия колонки:

давление газа-носителя (гелия) на входе в колонку - 1,8-2,4 ка/см²

деление газовых потоков на входе в колонку - $\sim 1: 200$

скорость газа-носителя

$-0,2-0,3 \mathrm{\mu л/мuн}$

температура колонки

$-80-160 \pm 0,2^{\circ}$

Опыты проводили в течение пяти месяцев. Характеристики колонки за это время не изменились.

Методика расчета мертвого объема колонки и индексов удерживания $I$ описаны в [']. Воспроизводимость измерений, рассчитанная как стандартное отклонение по пяти (не менее) измерениям при каждой температуре, составляла $\pm 0,3$ ед. (единиц индекса удерживания). В табл. 1 приведены индексы удерживания $I$-алкинов $\mathrm{C}_{6}-\mathrm{C}_{14}$ на ПЭГ $20 \mathrm{M}$.

\section{Обсуждение результатов}

Разделение изомеров. Индексы удерживания $I$ н-алкинов на ПЭГ $20 \mathrm{M}$ на 3-6 ед. меньше, чем на ПЭГ 4000 ['].

Порядок элюирования и разделение $H$-алкинов $\mathrm{C}_{10}-\mathrm{C}_{14}$ показаны на рис. 1, откуда видно, что на ПЭГ 20M изомерные $\mathrm{H}$-алкины элюируются в таком же порядке, как и на ПЭГ 4000: 7-, 6-, 5-, 4-, 3-, 1- и 2 -алкины. Разделенными оказались все изомеры $\mathcal{H}$-алкинов, кроме 4и 5-децинов и 5- и 6-додецинов. Такая же степень разделения была получена и на высокополярном 1,2,3-трис (2-цианэтокси)пропане [ $\left.{ }^{4}\right]$.

В табл. 2 приведены разности между индексами удерживания $d I$ соседних пар н-алкинов при $110^{\circ}$. Зависимость $d I$ от числа углеродных атомов в молекуле $n$ иллюстрируют графики на рис. 2. Величины $d I_{2} / 1$ уменьшаются, а у других пар н-алкинов увеличиваются в среднем на 1,0 ед, на $\mathrm{CH}_{2}$-группу, т, е. также, как на ПЭГ 4000, разделение $н$-алки- 
Величины $I$ для $\boldsymbol{\mu}$-алкинов $\mathrm{C}_{6}-\mathrm{C}_{14}$

\begin{tabular}{l|l|l|l|l|l|l|l|l|l|l}
\hline & \multicolumn{8}{|c}{ Температура, ${ }^{\circ} \mathrm{C}$} \\
\cline { 2 - 6 } & 80 & 90 & 100 & $110^{*}$ & 120 & 130 & 140 & 150 & 160 \\
\hline
\end{tabular}

\begin{tabular}{|c|c|c|c|c|c|c|c|c|c|}
\hline $\begin{array}{l}\text { 1-Гексин } \\
2 \text {-Гексин } \\
3 \text {-Гексин }\end{array}$ & $\begin{array}{l}830,0 \\
859,6 \\
824,1\end{array}$ & $\begin{array}{l}827,4 \\
859,4 \\
823,5\end{array}$ & $\begin{array}{l}825,8 \\
859,0 \\
822,3\end{array}$ & $\begin{array}{l}823,7 \\
858,8 \\
821,6\end{array}$ & & & & & \\
\hline $\begin{array}{l}\text { 1-Гептин } \\
2 \text {-Гептинн } \\
3 \text {-Гептин }\end{array}$ & $\begin{array}{l}930,4 \\
960,4 \\
910,3\end{array}$ & $\begin{array}{l}928,9 \\
960,3 \\
909,5\end{array}$ & $\begin{array}{l}927,5 \\
960,3 \\
908,2\end{array}$ & $\begin{array}{l}926,9 \\
960,8 \\
907,0\end{array}$ & & & & & \\
\hline 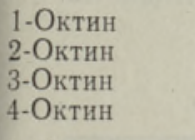 & $\begin{array}{r}1030,0 \\
1060,0 \\
1008,6 \\
966,0\end{array}$ & $\begin{array}{r}1028,5 \\
1059,5 \\
1008,1 \\
995,9\end{array}$ & $\begin{array}{r}1027,9 \\
1060,0 \\
1007,6 \\
994,9\end{array}$ & $\begin{array}{r}1027,1 \\
1060,4 \\
1006,9 \\
994,5\end{array}$ & $\begin{array}{r}1025,8 \\
1060,1 \\
1006,6 \\
994,2\end{array}$ & & & & \\
\hline $\begin{array}{l}\text { 1-Нонин } \\
\text { 2-Нонин } \\
\text { 3-Нонин } \\
\text { 4-Нонин }\end{array}$ & $\begin{array}{l}1130,1 \\
1157,0 \\
1105,8 \\
1091,9\end{array}$ & $\begin{array}{l}1128,9 \\
1157,3 \\
1105,5 \\
1091,8\end{array}$ & $\begin{array}{l}1128,5 \\
1158,3 \\
1105,2 \\
1091,7\end{array}$ & $\begin{array}{l}1127,8 \\
1158,3 \\
1104,9 \\
1091,6\end{array}$ & $\begin{array}{l}1126,8 \\
1158,5 \\
1104,9 \\
1091,8\end{array}$ & $\begin{array}{l}1126,5 \\
1159,5 \\
1104,1 \\
1091,1\end{array}$ & & & \\
\hline $\begin{array}{l}1 \text {-Децин } \\
2 \text {-Децин } \\
3 \text {-Децин } \\
4 \text {-Децин } \\
5 \text {-Децин }\end{array}$ & $\begin{array}{l}1228,8 \\
1255,6 \\
1202,6 \\
1187,0 \\
1185,5\end{array}$ & $\begin{array}{l}1228,6 \\
1256,7 \\
1202,7 \\
1187,1 \\
1185,8\end{array}$ & $\begin{array}{l}1228,3 \\
1257,5 \\
1202,9 \\
1187,6 \\
1186,4\end{array}$ & $\begin{array}{l}1227,9 \\
1258,4 \\
1202,9 \\
1187,8 \\
1186,5\end{array}$ & $\begin{array}{l}1227,4 \\
1259,1 \\
1202,7 \\
1187,6 \\
1186,5\end{array}$ & $\begin{array}{l}1227,3 \\
1259,9 \\
1202,6 \\
1187,8 \\
1186,7\end{array}$ & $\begin{array}{l}1226,8 \\
1259,8 \\
1202,5 \\
1187,8 \\
1186,9\end{array}$ & & \\
\hline 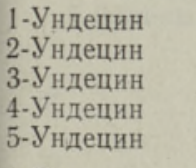 & & & $\begin{array}{l}1328,1 \\
1356,8 \\
1301,7 \\
1284,2 \\
1280,7\end{array}$ & $\begin{array}{l}1328,1 \\
1357,9 \\
1302,0 \\
1284,7 \\
1281,6\end{array}$ & $\begin{array}{l}1327,8 \\
1358,6 \\
1301,6 \\
1284,9 \\
1281,2\end{array}$ & $\begin{array}{l}1327.5 \\
1358,6 \\
1301,1 \\
1285,0 \\
1281,4\end{array}$ & $\begin{array}{l}1327,2 \\
1360,0 \\
1300,8 \\
1285,3 \\
1281,7\end{array}$ & $\begin{array}{l}1326,8 \\
1360,9 \\
1300,2 \\
1285,8 \\
1281,5\end{array}$ & $\begin{array}{l}1326,3 \\
1361,4 \\
1299,9 \\
1285,5 \\
1282,4\end{array}$ \\
\hline $\begin{array}{l}\text { 1-Додецин } \\
2 \text {-Додецин } \\
\text { 3-Додецин } \\
4 \text {-Додецин } \\
\text { 5-Додецин } \\
\text { 6-Додецин }\end{array}$ & & & $\begin{array}{l}1428,1 \\
1456,7 \\
1400,5 \\
1381,5 \\
1377,3 \\
1375,4\end{array}$ & $\begin{array}{l}1428,1 \\
1457,5 \\
1400,4 \\
1382,1 \\
1378,2 \\
1376,4\end{array}$ & $\begin{array}{l}1427,9 \\
1458,5 \\
1400,9 \\
1382,7 \\
1378,6 \\
1377,1\end{array}$ & $\begin{array}{l}1427,7 \\
1459,9 \\
1401,2 \\
1383,2 \\
1378,9 \\
1377,7\end{array}$ & $\begin{array}{l}1427,3 \\
1460,1 \\
1401,3 \\
1383,4 \\
1379,0 \\
1378,2\end{array}$ & $\begin{array}{l}1427,2 \\
1460,9 \\
1401,2 \\
1383,7 \\
1379,6 \\
1378,8\end{array}$ & $\begin{array}{l}1427,2 \\
1461,1 \\
1401,2 \\
1384,1 \\
1380,0 \\
1379,3\end{array}$ \\
\hline $\begin{array}{l}\text { 1-Тридецин } \\
\text { 2-Тридецин } \\
\text { 3-Тридецин } \\
\text { 4-Тридецин } \\
\text { 5-Тридецин } \\
\text { 6-Тридецин }\end{array}$ & & & & $\begin{array}{l}1528,1 \\
1557,5 \\
1499,5 \\
1480,5 \\
1475,1 \\
1471,7\end{array}$ & $\begin{array}{l}1528,1 \\
1558,7 \\
1500,0 \\
1481,1 \\
1475,5 \\
1472,6\end{array}$ & $\begin{array}{l}1527,9 \\
1559,3 \\
1500,1 \\
1481,5 \\
1476,4 \\
1473,3\end{array}$ & $\begin{array}{l}1527,5 \\
1560,1 \\
1500,6 \\
1481,6 \\
1476,8 \\
1474,0\end{array}$ & $\begin{array}{l}1527,6 \\
1561,2 \\
1501,1 \\
1482,4 \\
1476,7 \\
1474,8\end{array}$ & $\begin{array}{l}1527,7 \\
1562,1 \\
1501,0 \\
1482,7 \\
1477,5 \\
1475,5\end{array}$ \\
\hline $\begin{array}{l}\text { 1-Тетрадецин } \\
\text { 2-Тетрадецин } \\
\text { 3-Тетрадецин } \\
\text { 4-Тетрадецин } \\
\text { 5-Тетрадецин } \\
\text { 6-Тетрадецин } \\
\text { 7-Тетрадецин }\end{array}$ & & & & $\begin{array}{l}1628,3 \\
1657,9 \\
1599,5 \\
1579,4 \\
1573,1 \\
1568,5 \\
1567,3\end{array}$ & $\begin{array}{l}1628,6 \\
1659,1 \\
1599,9 \\
1580,1 \\
1573,9 \\
1569,2 \\
1568,3\end{array}$ & $\begin{array}{l}1628,1 \\
1659,6 \\
1600,0 \\
1580,9 \\
1574,5 \\
1570,4 \\
1568,6\end{array}$ & $\begin{array}{l}1627,4 \\
1660,2 \\
1600,2 \\
1580,9 \\
1575,6 \\
1570,6 \\
1569,5\end{array}$ & $\begin{array}{l}1628,1 \\
1661,6 \\
1600,7 \\
1582,0 \\
1575,7 \\
1571,8 \\
1570,0\end{array}$ & $\begin{array}{l}1628,3 \\
1662,4 \\
1600,7 \\
1582,2 \\
1576.5 \\
1572,0 \\
1570.8\end{array}$ \\
\hline
\end{tabular}

* Индексы удерживания $\mu$-гексинов, $H$-тридецинов и $\mu$-тетрадецинов при $110^{\circ} \mathrm{C}$ рассчитаны по формуле $I=A+B / T$.

нов с внутренней тройной связью улучшается с удлинением углеродной цепи. С повышением же температуры разделение этих изомеров $\boldsymbol{H}$-алкинов ухудшается.

Зависимость индексов удерживания от числа атомов углерода в молекуле н-алкина и от температуры. Для выявления корреляций между $I$ и $n$ экспериментальные данные были обработаны по уравнениям 


$$
\begin{gathered}
I=a+b n, \\
I=a^{\prime}+b^{\prime} n+c^{\prime} n^{2} .
\end{gathered}
$$

Коэффициенты $a, b, a^{\prime}, b^{\prime}, c^{\prime}$, рассчитанные методом наименьших квадратов на ЭВМ 1010В, приведены в табл. 3 и 4 соответственно.

Расхождения экспериментально измеренных значений $I$ с рассчитанными по уравнениям (1) и (2) составляют в среднем $0,05 \%$ (отн.) и $0,03 \%$ (отн.) соответственно, т. е. более точным является уравнение (2). Однако, учитывая незначительность расхождений, для практических расчетов целесообразнее пользоваться формулой (1) как более простой.

Инкременты $I$ на $\mathrm{CH}_{2}$-группу $\left(I_{\mathrm{CH}_{2}}\right)$ H-алкинов $\mathrm{C}_{6}-\mathrm{C}_{14}$ на ПЭГ $20 \mathrm{M}$ (табл. 5) не отличаются от соответствующих значений, полученных на ПЭГ 4000, и изменяются по тем же закономерностям ['].

Таблица 2

\begin{tabular}{|c|c|c|c|c|c|c|}
\hline \multirow{2}{*}{$n$} & \multicolumn{6}{|c|}{ Положение тройной связи в молекуле } \\
\hline & $2 / 1$ & $1 / 3$ & $3 / 4$ & $4 / 5$ & $5 / 6$ & $6 / 7$ \\
\hline $\begin{array}{r}6 \\
7 \\
8 \\
9 \\
10 \\
11 \\
12 \\
13 \\
14\end{array}$ & $\begin{array}{l}35,1 \\
33,9 \\
33,3 \\
30,5 \\
30,5 \\
29,8 \\
29,4 \\
29,4 \\
29,6\end{array}$ & $\begin{array}{r}2,1 \\
19,9 \\
20,2 \\
22,9 \\
25,0 \\
26,1 \\
27,7 \\
28,6 \\
28,8\end{array}$ & $\begin{array}{l}12,4 \\
13,3 \\
15,1 \\
17,3 \\
18,3 \\
19,0 \\
20,1\end{array}$ & $\begin{array}{l}1,3 \\
3,1 \\
3,9 \\
5,4 \\
6,3\end{array}$ & $\begin{array}{l}1,8 \\
3,4 \\
4,6\end{array}$ & 1,2 \\
\hline
\end{tabular}

Величины $d I$ для соседних пар $\boldsymbol{н}$-алкинов $\mathrm{C}_{6}-\mathrm{C}_{14}$ при $110^{\circ} \mathrm{C}$

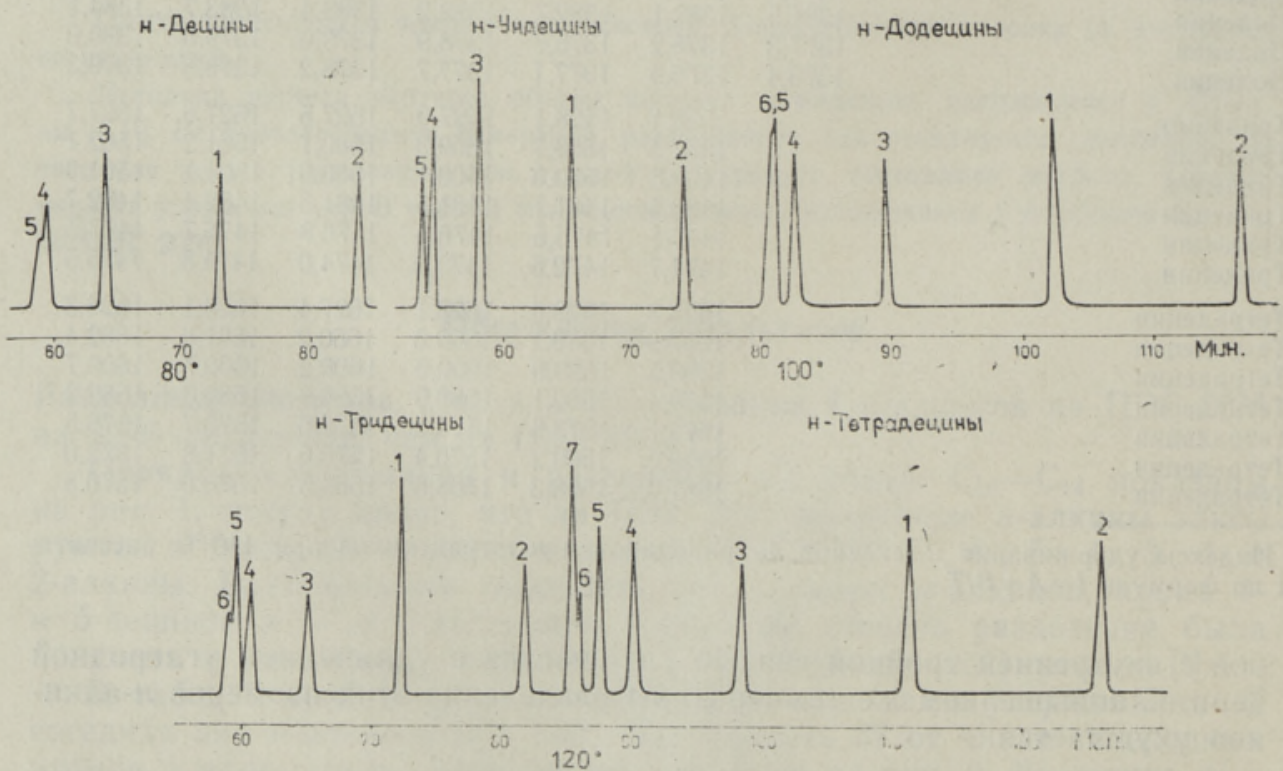

Рис. 1. Хроматограммы $н$-алкинов $\mathrm{C}_{10}-\mathrm{C}_{14}$. Номера у пиков обозначают положение тройной связи в молекуле, 
Таблица 3

Коэффициенты уравнения (1) для $\boldsymbol{k}$-алкинов $\mathrm{C}_{6}-\mathrm{C}_{14}$

\begin{tabular}{|c|c|c|c|c|c|c|}
\hline \multirow{2}{*}{ Углеводород } & \multicolumn{2}{|c|}{$100^{\circ} \mathrm{C}$} & \multicolumn{2}{|c|}{$110^{\circ} \mathrm{C}$} & \multicolumn{2}{|c|}{$120^{\circ} \mathrm{C}$} \\
\hline & $a$ & $b$ & $a$ & $b$ & $a$ & $b$ \\
\hline $\begin{array}{l}\text { 1-Алкины } \\
\text { 2-Алкины } \\
\text { 3-Алкины } \\
\text { 4-Алкины } \\
\text { 5-Алкины } \\
6 \text {-Алкины }\end{array}$ & $\begin{array}{l}225,0 \\
263,6 \\
233,6 \\
222,3 \\
231,5\end{array}$ & $\begin{array}{r}100,3 \\
99,4 \\
97,0 \\
96,6 \\
95,4\end{array}$ & $\begin{array}{l}225,2 \\
265,4 \\
217,5 \\
219,3 \\
227,8\end{array}$ & $\begin{array}{r}100,3 \\
99,3 \\
98,6 \\
96,8 \\
95,8\end{array}$ & $\begin{array}{l}223,0 \\
260,2 \\
214,8 \\
213,0 \\
216,2 \\
224,3\end{array}$ & $\begin{array}{r}100,4 \\
99,9 \\
98,9 \\
97,6 \\
96,9 \\
96.1\end{array}$ \\
\hline
\end{tabular}

Коэффициенты уравнения (2) для $\boldsymbol{\mu}$-алкинов $\mathrm{C}_{6}-\mathrm{C}_{14}$

\begin{tabular}{|c|c|c|c|c|c|c|c|c|c|}
\hline \multirow{2}{*}{ Углеводород } & \multicolumn{3}{|c|}{$100^{\circ} \mathrm{C}$} & \multicolumn{3}{|c|}{$110^{\circ} \mathrm{C}$} & \multicolumn{3}{|c|}{$120^{\circ} \mathrm{C}$} \\
\hline & $a^{\prime}$ & $b^{\prime}$ & $c^{\prime}$ & $a^{\prime}$ & $b^{\prime}$ & $c^{\prime}$ & $a^{\prime}$ & $b^{\prime}$ & $c^{\prime}$ \\
\hline $\begin{array}{l}\text { 1-Алкины } \\
\text { 2-Алкины } \\
\text { 3-Алкины } \\
\text { 4-Алкины } \\
\text { 5-Алкины }\end{array}$ & $\begin{array}{l}213,0 \\
257,4 \\
290,2 \\
234,2\end{array}$ & $\begin{array}{r}103,1 \\
100,9 \\
83,8 \\
94,1\end{array}$ & $\begin{array}{c}-0,156 \\
-0,0131 \\
0,73 \\
0,12\end{array}$ & $\begin{array}{l}220,5 \\
275,4 \\
212,7 \\
228,9\end{array}$ & $\begin{array}{r}101,3 \\
97,1 \\
99,6 \\
95,0\end{array}$ & $\begin{array}{r}-0,054 \\
0,114 \\
-0,055 \\
0,093\end{array}$ & $\begin{array}{l}215,4 \\
272,5 \\
236,1 \\
242,3 \\
286,2\end{array}$ & $\begin{array}{r}101,7 \\
97,6 \\
94,9 \\
92,1 \\
85,1\end{array}$ & $\begin{array}{r}-0,361 \\
0,105 \\
0,182 \\
0,250 \\
0,493\end{array}$ \\
\hline
\end{tabular}

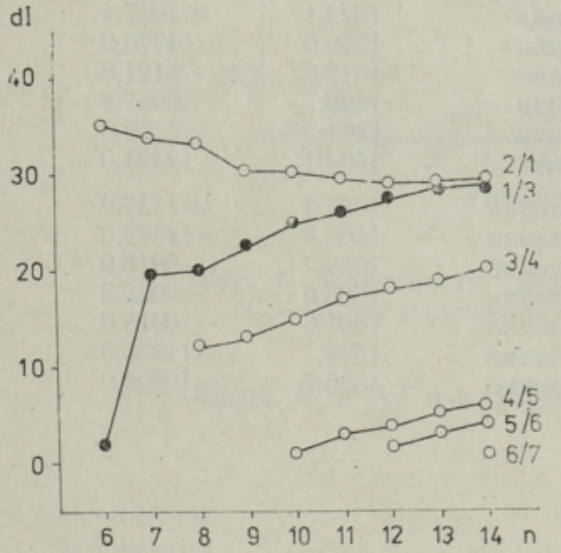

Рис. 2. Зависимость разностей между индексами удерживания $d I$ соседних пар родных атомов $n$ в молекуле при $110^{\circ} \mathrm{C}$. Здесь и на рис. 3,4 номера у линий обозначают положение тройной связи в молекуле.

Рис. 3. Зависимость индексов удерживания $I$ н-додецинов от обратной температуры $1 / T$.

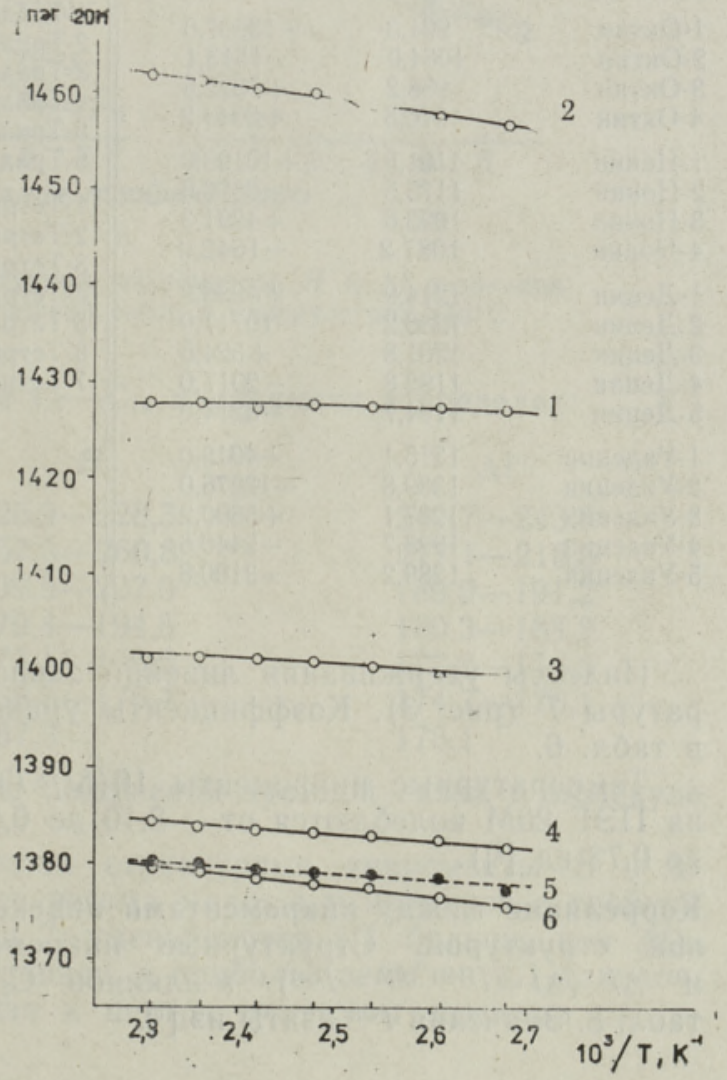


Величины $\boldsymbol{I}_{\mathrm{CH}_{2}}$ для $\boldsymbol{\mu}$-алкинов $\mathrm{C}_{6}-\mathrm{C}_{14}$ при $110^{\circ} \mathrm{C}$

\begin{tabular}{c|r|r|r|r|r|c}
\hline \multirow{2}{*}{$n$} & \multicolumn{5}{|c}{ Положение тройной связи в молекуле } \\
\cline { 2 - 7 } & 1 & 2 & 3 & 4 & 5 & 6 \\
\hline & 103,2 & 102,0 & 85,4 & & & \\
$7 \rightarrow 7$ & 100,2 & 99,6 & 99,9 & & & \\
$8 \rightarrow 8$ & 100,7 & 97,9 & 98,0 & 97,1 & & \\
$9 \rightarrow 10$ & 100,1 & 100,1 & 98,0 & 96,2 & \\
$10 \rightarrow 11$ & 100,2 & 99,5 & 99,1 & 96,9 & 95,1 & \\
$11 \rightarrow 12$ & 100,0 & 99,6 & 98,4 & 97,4 & 96,6 & \\
$12 \rightarrow 13$ & 100,0 & 100,0 & 99,1 & 98,4 & 96,9 & 95,3 \\
$13 \rightarrow 14$ & 100,2 & 100,4 & 100,0 & 98,9 & 98,0 & 97,8
\end{tabular}

Таблица 6

Коэффициенты уравнения $\boldsymbol{I}=\boldsymbol{A}+\boldsymbol{B} / \boldsymbol{T}\left[{ }^{2}\right]$ для $\boldsymbol{\boldsymbol { H }}$-алкинов $\mathrm{C}_{6}-\mathrm{C}_{14}$

\begin{tabular}{|c|c|c|c|c|c|}
\hline Углеводород & $A$ & B & Углеводород & $A$ & B \\
\hline $\begin{array}{l}\text { 1-Гексин } \\
2 \text {-Гексин } \\
3 \text {-Гексин }\end{array}$ & $\begin{array}{l}751,3 \\
848,5 \\
790,7\end{array}$ & $\begin{array}{r}+27726,0 \\
+3940,2 \\
+11820,0\end{array}$ & \multirow{2}{*}{$\begin{array}{l}1 \text {-Додецин } \\
2 \text {-Додецин } \\
3 \text {-Додецин } \\
4 \text {-Додецин } \\
5 \text {-Додецин } \\
6 \text {-Додецин }\end{array}$} & \multirow{2}{*}{$\begin{array}{l}1420,3 \\
1492,5 \\
1406,9 \\
1399,8 \\
1395,0 \\
1402,9\end{array}$} & \multirow{2}{*}{$\begin{array}{r}+2942,3 \\
-13381,0 \\
-2405,7 \\
-6794,6 \\
-6548,0 \\
-10200,0\end{array}$} \\
\hline 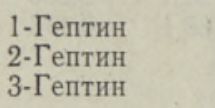 & $\begin{array}{l}884,5 \\
964,7 \\
867,6\end{array}$ & $\begin{array}{r}+16160,0 \\
-1579,1 \\
+15118,0\end{array}$ & & & \\
\hline $\begin{array}{l}\text { 1-Октин } \\
\text { 2-Октин } \\
\text { 3-Октин } \\
\text { 4-Октин }\end{array}$ & $\begin{array}{r}991,3 \\
1064,0 \\
988,2 \\
976,5\end{array}$ & $\begin{array}{r}+13607,0 \\
-1513,1 \\
+7222,5 \\
+6944,2\end{array}$ & $\begin{array}{l}\text { 1-Тридецин } \\
\text { 2-Тридецин } \\
\text { 3-Тридецин } \\
\text { 4-Тридецин } \\
\text { 5-Тридецин }\end{array}$ & $\begin{array}{l}1523,1 \\
1596,0 \\
1512,9 \\
1498,7 \\
1494,3\end{array}$ & $\begin{array}{r}+1917,4 \\
-14770,0 \\
-5121,6 \\
-6957,8 \\
-73496\end{array}$ \\
\hline \multirow{2}{*}{$\begin{array}{l}\text { 1-Нонин } \\
\text { 2-Нонин } \\
\text { 3-Нонин } \\
\text { 4-Нонин }\end{array}$} & \multirow{2}{*}{$\begin{array}{l}1101,0 \\
1175,5 \\
1093,6 \\
1087,2\end{array}$} & \multirow{2}{*}{$\begin{array}{r}+10193,0 \\
-6576,6 \\
+4291,3 \\
-1642,0\end{array}$} & 6-Тридецин & 1504,1 & $-12421,0$ \\
\hline & & & \multirow{3}{*}{$\begin{array}{l}\text { 1-Тетрадецин } \\
\text { 2-Тетрадецин } \\
\text { 3-Тетрадецин } \\
\text { 4-Тетрадецин } \\
\text { 5-Тетрадецин } \\
\text { 6-Тетрадецин } \\
\text { 7-Тетрадецин }\end{array}$} & \multirow{3}{*}{$\begin{array}{l}1625,3 \\
1695,9 \\
1609,7 \\
1603,0 \\
1601,6 \\
1599,7 \\
1595,7\end{array}$} & \multirow{3}{*}{$\begin{array}{r}+1137,0 \\
-14579,0 \\
-3910,0 \\
-9025,3 \\
-10918,0 \\
-11956,0 \\
-10868,0\end{array}$} \\
\hline $\begin{array}{l}1 \text {-Децин } \\
2 \text {-Децин } \\
3 \text {-Децин } \\
4 \text {-Децин } \\
5 \text {-Децин }\end{array}$ & $\begin{array}{l}1214,9 \\
1286,2 \\
1201,8 \\
1192,8 \\
1194,7\end{array}$ & $\begin{array}{r}+4936,9 \\
-10717,0 \\
+324,6 \\
-2017,0 \\
-3214,0\end{array}$ & & & \\
\hline 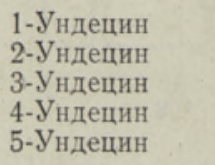 & $\begin{array}{l}1315,1 \\
1389,8 \\
1287,1 \\
1298,7 \\
1289,2\end{array}$ & $\begin{array}{r}+4918,0 \\
-12276,0 \\
+5600,2 \\
-5440,6 \\
-3100,8\end{array}$ & & & \\
\hline
\end{tabular}

Индексы удерживания линейно зависят также от обратной температуры $T$ (рис. 3 ). Коэффициенты уравнения $I=A+B / T\left[{ }^{2}\right]$ приведены в табл. 6.

Температурные инкременты $10(\delta I / \delta T) \quad H$-алкинов $\mathrm{C}_{6}-\mathrm{C}_{14}$ (табл. 7) на ПЭГ 20М колеблются от $-2,10$ до 0,87 ед. (на ПЭГ 4000 от $-1,93$ до 0,73 ед. $\left.\left.{ }^{2}\right]\right)$.

Корреляции между инкрементами индексов удерживания и молекулярной структурой. Структурные инкременты $H\left(H=I_{H \text {-алкия }}-I_{H \text {-алкаң }}\right)$

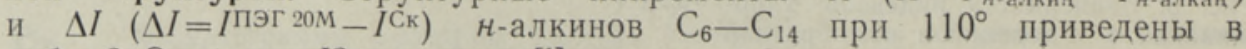
табл. 8. Значения $I^{\text {Ск }}$ взяты из [']. 


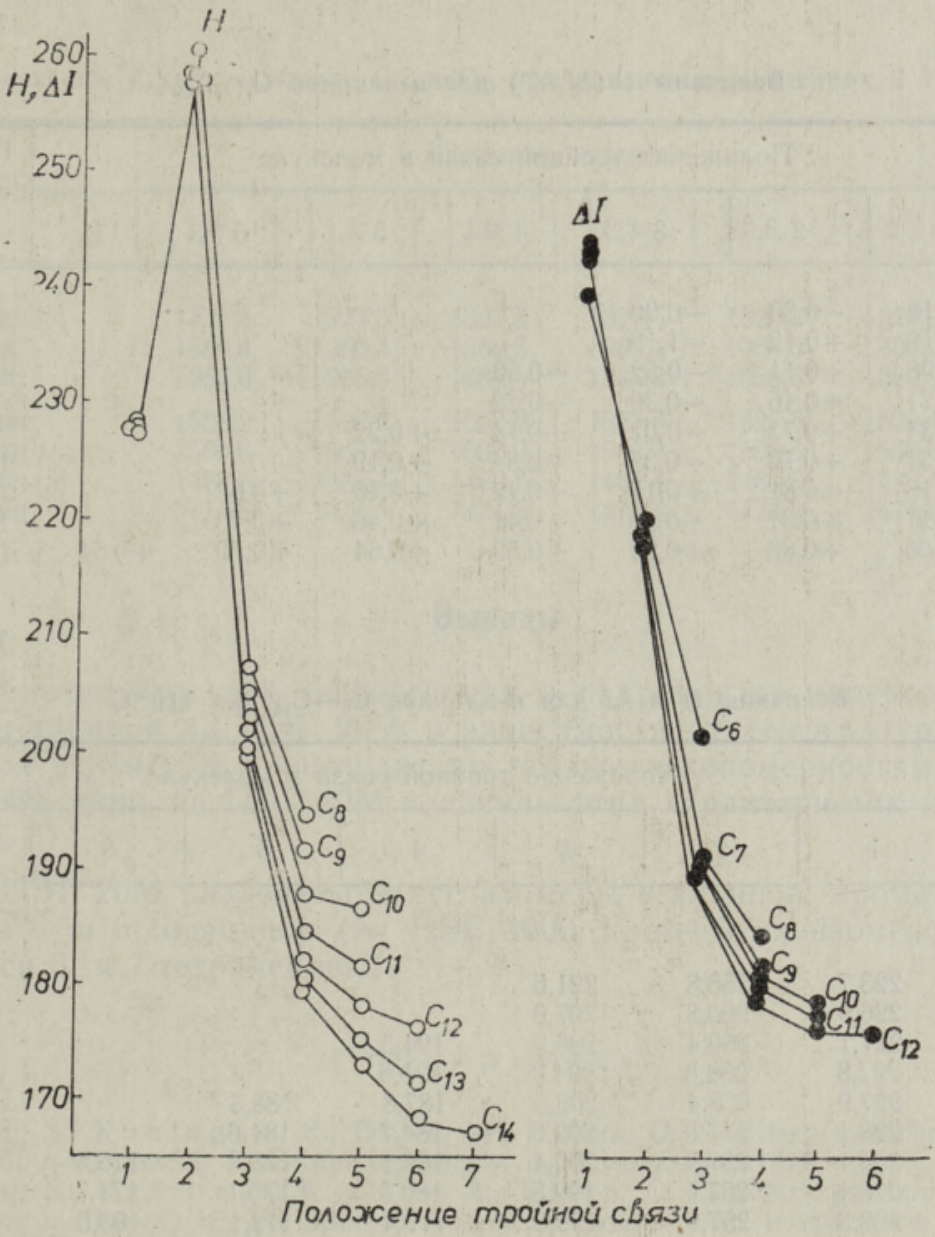

Рис. 4. Зависимость структурных инкрементов $H$ и $\Delta I H$-алкинов $\mathrm{C}_{6}-\mathrm{C}_{14}$ от положения тройной связи в молекуле при $110^{\circ} \mathrm{C}$.

Величины $H$ и $\Delta I$-алкинов $\mathrm{C}_{7}-\mathrm{C}_{14}$ изменяются в пределах:

\section{H}

$226,9-228,3$

$257,5-260,8$

$199,5-207,0$

$179,4-194,5$

$173,1-186,5$

$168,5-176,4$

167,3
$\Delta I$

$242,7-243,9$

$217,1-218,8$

$189,0-191,2$

$180,3-184,2$

$177,3-178,5$

$174,7-176,1$

175,1

6-Алкинь

Зависимости $H$ и $\Delta I$ от $n$ и положения тройной связи в молекуле при $110^{\circ}$ изображены на рис. 4 .

С удлинением углеродной цепи структурные инкременты $H$ и $\Delta I$ у 1-, 2- и 3-алкинов изменяются весьма мало, а у изомеров с тройной связью в положениях $4,5,6$ и 7 уменьшаются ( $H$ больше, чем $\Delta I)$. Наибольшие величины $H$ у 2 -алкинов, а наибольшие $\Delta I-$ у 1 -алкинов. С передвижением тройной связи к центру молекулы значения струк- 
таблица 7

Величины $10(\delta I / \delta T)$ для $\boldsymbol{\mu}$-алкинов $\mathrm{C}_{6}-\mathrm{C}_{14}$

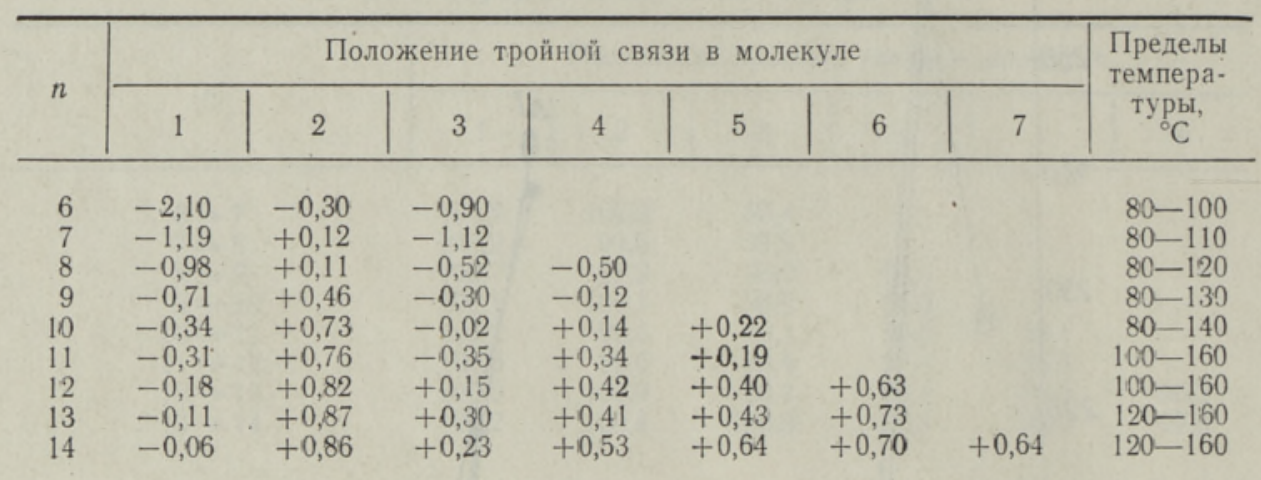

таблица 8

Величины $\boldsymbol{H}$ и $\Delta \boldsymbol{I}$ для $\boldsymbol{H}$-алкинов $\mathrm{C}_{6}-\mathrm{C}_{14}$ при $110^{\circ} \mathrm{C}$

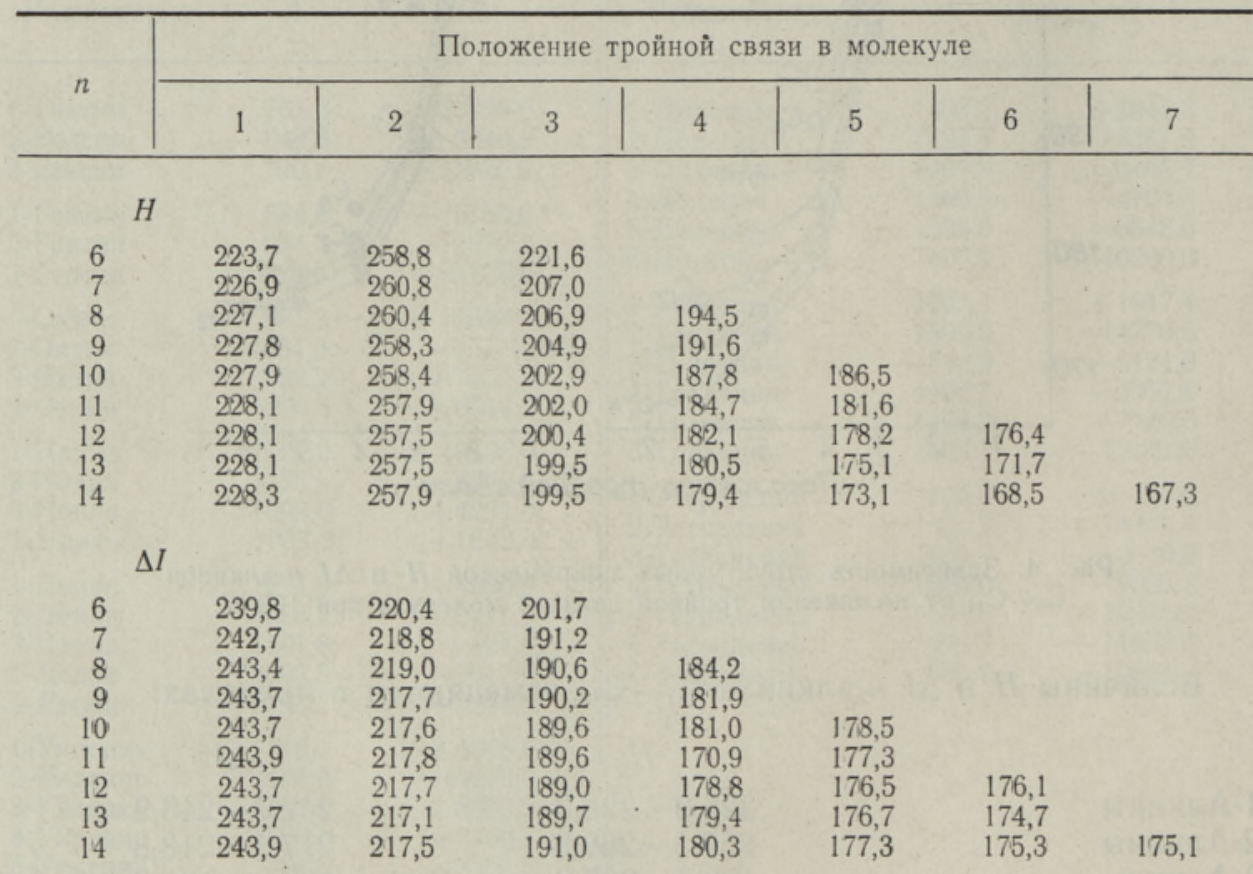

турных инкрементов уменьшаются $(H$ больше, чем $\Delta I)$. $H$-Алкины с тройной связью в положениях 5, 6 и 7 имеют близкие значения $H$ и $\Delta I$.

Зависимость индексов удерживания от давления газа-носителя. Давление гелия на входе в колонку изменялось в пределах $1,4-3,0$ кг/c ${ }^{2}$. Результаты исследования для некоторых $H$-ундецинов и $H$-тридецинов при $140^{\circ}$ приведены в табл. 9. Видно, что с ростом давления величины $I$ (средние значения пяти измерений) уменьшаются весьма незначительно - в среднем на 0,2 ед. на $1,0 \kappa 2 / c \mu^{2}$, что не превышает средней погрешности определения индексов ( 0,3 ед.). 
Величины $I$ для $\boldsymbol{u}$-алкинов $\mathrm{C}_{11}$ и $\mathrm{C}_{13}$ при различных давлениях и $140^{\circ} \mathrm{C}$

\begin{tabular}{|c|c|c|c|c|c|c|c|}
\hline \multirow{2}{*}{ Углеводород } & \multicolumn{6}{|c|}{ Давление, кә/см ${ }^{2}$} & \multirow{2}{*}{$\delta I / \delta P$} \\
\hline & 1,4 & 1,7 & 2,0 & 2,3 & 2,6 & 3,0 & \\
\hline 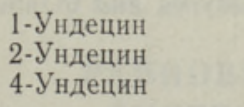 & $\begin{array}{l}1327,4 \\
1360,4 \\
1285,6\end{array}$ & $\begin{array}{l}1327,6 \\
1360,4 \\
1285,6\end{array}$ & $\begin{array}{l}1327,5 \\
1360,5 \\
1285,6\end{array}$ & $\begin{array}{l}1327,5 \\
1360,4 \\
1285,2\end{array}$ & $\begin{array}{l}1326,8 \\
1360,0 \\
1285,5\end{array}$ & $\begin{array}{l}1326,9 \\
1360,0 \\
1285,9\end{array}$ & $\begin{array}{l}-0,35 \\
-0,27 \\
+0,13\end{array}$ \\
\hline $\begin{array}{l}\text { 1-Тридецин } \\
\text { 2-Тридецин } \\
\text { 4-Тридецин } \\
\text { 6-Тридецин }\end{array}$ & $\begin{array}{l}1528,2 \\
1560,8 \\
1482,6 \\
1474,8\end{array}$ & $\begin{array}{l}1528,2 \\
1560,6 \\
1482,4 \\
1474,6\end{array}$ & $\begin{array}{l}1528,2 \\
1560,9 \\
1482,5 \\
1474,5\end{array}$ & $\begin{array}{r}1527,8 \\
1560,5 \\
-1482,4 \\
1474,5\end{array}$ & $\begin{array}{l}1527,8 \\
1560,5 \\
1481,9 \\
1474,2\end{array}$ & $\begin{array}{l}1528,1 \\
1560,6 \\
1482,6 \\
1474,4\end{array}$ & $\begin{array}{l}-0,12 \\
-0,15 \\
-0,12 \\
-0,27\end{array}$ \\
\hline
\end{tabular}

\section{Выводы}

1. Изменение индексов удерживания и инкрементов индексов удерживания $\boldsymbol{\mu}$-алкинов на ПЭГ $20 \mathrm{M}$ в зависимости от температуры и молекулярной структуры происходит по тем же закономерностям, что и на ПЭГ 4000, лишь на ПЭГ 20 М величины этих характеристик на 3-6 ед. меньше.

2. На ПЭГ $20 \mathrm{M}$ разделяются все изомеры $н$-алкинов, кроме 4- и 5-децинов и 5- и 6-додецинов (на ПЭГ 4000, кроме этих изомеров, не разделяются 6- и 7-тетрадецины).

\section{ЛИТЕ Р А Т У Р А}

1. R a ng, S., Kun ing a s, K., O r a v, A., E i s e n, O. Capillary gas chromatography of $n$-alkynes. I. Retention indices. - J. Chromatogr., 1976, v. 119, p. $451-460$.

2. R a n g, S., Kun ing a s, K., Orav, A., E is en, O. Capillary gas chromatography of $n$-alkynes. II. Variation of retention indices with temperature. - J. Chromatogr., 1976 , v. $128, \mathrm{~N} 1$, p. $53-58$.

3. Ra ng, S., Kun ing a s, K., Ora v, A., E is e n, O. Capillary gas chromatography of $n$-alkynes. III. Correlation of retention index increments with molecular structure. - J. Chromatogr., 1976, v. 128, N 1, p. 59-63.

4. Ор ав А., Кунинга С К., Р анг С., Э йз ен О. Капиллярная газсвая хроматография $н$-алкинов на 1,2,3-трис (2-цианэтокси) пропане. - Изв. АН ЭССР. Хим., 1980 , т. 29 , № 3, c. $177-184$.

Ннститут химии

Академии наук Эстонской ССР
Поступила в редакцию 19/XI 1979

\section{n-ALKUUNIDE KAPILLAARGAASIKROMATOGRAAFIA POLUETULEENGLOKOOLIL 20M}

On ésitatud $100 \mathrm{~m}$ pikkuse polüetüleenglükooli $20 \mathrm{M}$ kolonni abil määratud $n$-alküünide $\mathrm{C}_{6}-\mathrm{C}_{14}$ retentsiooniindeksid, nende temperatuuri- ja struktuuriinkremendid ning nimetatud suuruste korrelatsioon molekuli ehitusega. Tulemusi on vôrreldud polüetüleenglükoolil 4000 saadud analoogiliste andmetega. PEG 20M kolonniga on lahutatud kõik n-alküünide $\mathrm{C}_{6}-\mathrm{C}_{16}$ isomeerid, välja arvatud 4- ja 5-detsüün ning 5-ja 6-dodetsüün. 
Anne ORAV, Kai KUNINGAS, Silvia RANG, O. EISEN

\section{CAPILLARY GAS CHROMATOGRAPHY OF $n$-ALKYNES ON POLYETHYLENE GLYCOL 20M}

Retention indices $I$, temperature and structural increments of $I$ for $C_{6}-C_{14} n$-alkynes on polyethylene glycol (PEG) $20 \mathrm{M}$ capillary column are presented and correlated with the structure of isomers. The results are compared with analogous data on PEG 4000. On PEG 20M all isomers of $n$-alkynes are separated, except 4- and 5-decynes and 5- and 6-dodecynes. 